\title{
Impact of Urban Landscape on Human Well-being as a Tool for Achievement of Sustainable Development
}

\author{
Mir Saeed Moosavi ${ }^{1}$, Fatemeh Jafari ${ }^{2}$, Laleh Davatgar Badie ${ }^{3}$
}

\begin{abstract}
The urbanized world is facing unprecedented social-demographic, technological and environmental changes and in the face of these changes, an important set of questions arises related to how to plan and manage urban green spaces for the benefit of both urban dwellers and biodiversity. The diversity and quality of urban green spaces and human well-being are tightly linked as urban green areas provide a number of benefits for people. This study aimed to promote the characters of natural environment as a platform to enhance human well-being in urban areas and mainly was conducted to determine the need of urban community related to urban parks. The findings of this research can be used as guiding reference in related areas to improve and enhance the quality of public spaces in urban parks as an urban environment to fulfill the needs and requirements of visitors.
\end{abstract}

Keywords: Landscape, Human, Sustainable, Urban.

\section{Introduction}

A landscape is the expression of the interaction between the natural environment and man's activities to make the environment more suitable for his life and needs (Antrop, 1998). Within urban areas, landscapes are highly affected and even dominated by human activities. The outward forms of those city landscapes have significant connections with their economic, social or cultural functions (Wu, 2006, 2010, 2014; Lin et al.,2016).

In the last few decades, newer fields integrating natural and social sciences have emerged to investigate urban systems and address complex problems. Urban ecology, an offshoot of ecology, is an interdisciplinary field that aims to understand the whole city as an ecosystem comprised of both humans and other living organisms that coexist inhumandominated systems (Wu, 2014; Gopal et al., 2016).

In new approach regarding urban ecology, landscape is a visible and noticeable artifact of often unnoticed and sometimes invisible natural and societal processes. Because landscapes are visible, landscape can bring different people into a common experience of environmental systems. Across all scales of environmental phenomena, the scale at which landscape patterns are perceived by humans, the "perceptible realm," is decisive for landscape change (Gobster et. al, 2007; Nassauer, 2012).

The "urban landscape" - considered as a dynamic organism - "comprises three main categories: monumental heritage of exceptional cultural value; non-exceptional heritage elements but present in a coherent way with a relative abundance; new urban elements to be considered (the urban built form; the open spaces, streets, public open spaces, urban 
infrastructure, material networks and equipment," (UNESCO, 2011). Specifically, the "historic urban landscape" approach moves beyond the preservation of the physical environment and focuses on the entire human environment with all of its tangible red intangible qualifies. It seeks to increase the sustainability of alarming and design interventions by taking Imo account the existing built environment, intangible heritage, cultural diversity, socio-economic and environmental factors along with local community values. The idea of "historic urban landscape" is the result of the layering and intertwining of cultural and natural satire over time. Besides the notion of "historic urban center", it includes the broader urban context and its geographical setting. The layer overlapped are: cultural practices, infrastructures, built environment, diversity and identity, geomorphology, urban structure, economic processes, topography, open space, social values, hydrology (UNESCO, 2011). This approach considers the urban landscape with its tangible and intangible components the key resource to improve urban quality and livability, to pursue economic development and social cohesion in a constantly changing global context. In particular, the UNESCO recommendations call for an integration of urban heritage protection strategies within the wider framework of sustainable development objectives (Ragozino, 2016).

The use of urban park, a newly added element to urban life, has changed over time. The need of individuals living in industrialized cities, in the transition to this new way of life, to bond with the nature in the form of green spaces resulted in use of public parks by the citizens. This transformation of public space from belonging mainly to the bourgeois into areas used by all citizens changed the definition of public space and its usage patterns. The design of landscaped spaces, that far mainly used as a tool to serve political power, after the Industrial revolution came under the influence of contemporary views of human beings and the social reality of urban life. Early pleasure gardens and the gardens of the courtly life were replaced by the public parks (1840-1900), then, parks as instrument of social reform (1900-1930), parks as active recreational facilities (19301965), and now open space systems serving both ecological and more passive recreational purposes (Cranz, 1989). Today, the changing concept of public park with new social, cultural, and symbolic meanings creates new relationships with the citizens and has a new mission in a modern world where the death of public space is in discussion (Uludağ, 1998; Ekinci \& Saglam, 2016).

This study aimed to promote the characters of natural environment as a platform to enhance human well-being in urban areas. The findings of this research can be used as guiding reference in related areas to improve and enhance the quality of public spaces in urban parks as an urban environment to fulfill the needs and requirements of visitors.

\section{Research Area}

This study involved two different urban parkas in Tabriz, a city in northwest of Iran as study areas. The first study area is Golestan Garden, a historical urban park located in historic area in city center, and the second study area is Elgoli Garden, an urban park with several natural features which was constructed as country recreational garden but now located in urban district.

Golestan Park is considered a historical and somewhat monumental park in Tabriz, Iran. 
The park is located near to Qonqa Square in city center. The place, which was originally used as a public cemetery, has changed to a city park during the second Pahlavi era. Golestan is also one of the most popular traditional neighborhoods in Tabriz. Located in the core of the most westerly part of the historical district of the city, Golestan district contains many historical buildings and spaces that are considered as important elements of the city's architectural and cultural heritage. The Golestan Garden Historic District is considered to be very significant in the historical, archeological, and architectural heritage of the Tabriz. This neighborhood completely reflects the city's growth from the traditional pattern of urban life to a modern society influenced by western culture, yet is able to demonstrate the importance of the an urban garden in city's history (Golzarian and Zarei, 2013).

Early history of the Elgoli is not clear. However, it seems that it was used as a water resource for agricultural purposes and it was used as a summer palace for recreation during the Qajar dynasty (when Tabriz was the official residence of Prince of Iran). It contains a palace that is surrounded by a great square water pool almost 12 meters deep. Elgoli (previously called Shahgoli) Park is also known as the "Old Park" in Tabriz (Wilber, 1979; Hami et al, 2011). This was later declared as a public urban park in 1930 (Romianfar, 2008; Hami et al, 2011). Elgoli covers an area of 60.7 Hectares (150 acres) (Ghorbani, 2006; Hami et al, 2011) and located in the Southwest part of Tabriz. In 1930, renovation was done to the park by Tabriz Municipality and it became a public park (Romianfar, 2008; Hami et al, 2011).

\section{Methodology}

In this research, in order to gain necessary information and data, methods like observation, quantitative survey, qualitative survey and data analysis were used. These methods have been useful to collect and search both primary and secondary data of the research. The observation was conducted as a pilot survey on selected parks to gain the information how urban dweller interacts with nature in urban parks.

After these observations, preparation of the survey involved the development of a questionnaire for the quantitative and qualitative survey of data. The survey included the visitors of both gardens. This qualitative survey was conducted in a face-to-face manner which was very important for getting instant feedback from the participants. From the qualitative survey also we could identify the problem which was not obvious through the observation. The quantitative survey involved the users and visitors of both gardens. Questionnaires consisted of the demographic, open-ended and closed-ended questions related to the subject and were based on attributes, variables or elements motivating people to visit and the degree the visitation can affect their wellbeing. Filling in the questionnaire was not obligatory, and only those who were willing to participate the survey filled up the form. Then, collected data were analyzed using the software of SPSS to be clearer and easy to understand. A general characterization of participants is summarized in Table 1. 
Table 1: Demographic Characterization of Participants

\begin{tabular}{|c|c|c|c|c|}
\hline Category & Golestan Park & & Elgoli Park & \\
\hline Number of participant & 281 participants & & 237 participants & \\
\hline Ethnic & Native & $41.6 \%$ & Native & $33.7 \%$ \\
\hline & Permanent resident & $39.9 \%$ & Permanent resident & $23.6 \%$ \\
\hline & Tourist & $18.5 \%$ & Tourist & $19.4 \%$ \\
\hline & & & Foreigner & $23.3 \%$ \\
\hline Gender & Male & $53 \%$ & Male & $62 \%$ \\
\hline & Female & $47 \%$ & Female & $38 \%$ \\
\hline Material status & Single & $53 \%$ & Single & $26 \%$ \\
\hline & Married & $47 \%$ & Married & $74 \%$ \\
\hline Education level & Primary school & $2.8 \%$ & Primary school & $0 \%$ \\
\hline & Lower secondary school & $4.5 \%$ & Lower secondary school & $11 \%$ \\
\hline & Upper secondary school & $18.2 \%$ & Upper secondary school & $9 \%$ \\
\hline & Diploma & $39.5 \%$ & Diploma & $17 \%$ \\
\hline & Bachelor degree & $25.2 \%$ & Bachelor degree & $58 \%$ \\
\hline & Master & $6.3 \%$ & Others & $5 \%$ \\
\hline & Ph.D & $3.5 \%$ & & \\
\hline Occupation & Public sector & $8.4 \%$ & Public sector & $38 \%$ \\
\hline & Private sector & $31.1 \%$ & Private sector & $46 \%$ \\
\hline & Self-employed & $28.0 \%$ & Self-employed & $10 \%$ \\
\hline & Student & $27.6 \%$ & Others & $6 \%$ \\
\hline & Retiree & $2.8 \%$ & & \\
\hline & Housewife & $1.7 \%$ & & \\
\hline & Unemployed & $0.4 \%$ & & \\
\hline
\end{tabular}

Most part of the criteria of the participants in both gardens had similarity and differences. The number of Golestan Garden participants are more than Elgoli Garden, which is 281 for Golestan Garden while 237 in Elgoli Garden.

\section{Findings}

The major reasons leading the participants to visit both gardens which are concluded from the open-ended survey showed that there must exist a strong reason for people to come to both gardens. From table 2 it becomes obvious that 90 participants $(32.02 \%)$ said that, the reason why they visited the Golestan garden is for recreational activities or exercise that showed the highest percentage for this garden. While for Elgoli garden, the majority or the highest range of reasons for visitors also was recreational activities or excersice with 107 participants $(45.14 \%)$. Beautiful place with historical background is the second highest reason $(\mathrm{f}=69,24.55 \%)$ that encouraged visitors to come to the Golestan garden during different times. The second highest result for the Elgoli garden was natural beauty of the area, and the result was $\mathrm{f}=81,34.18 \%$. Other than that, third reason was being with family and friends ( $f=58,20.65 \%$ ), fourth to enjoy the natural beauty $(\mathrm{f}=35,12.45 \%)$, and finally to release stress and relaxing were the main reasons for visiting the Golestan garden. The consequetive reasons for visitors of the 
Elgoli garden participants were meeting or dating ( $\mathrm{f}=23,9.70 \%$ ), to release stress and relaxing $(\mathrm{f}=22,9.29 \%)$ and finally the location of some amenities like restaurants nearby the Elgoli garden $(\mathrm{f}=4,1.69 \%)$. These results showed the similarity of the main reasons for inhabitants of Tabriz who visited both gardens. The results also proved that both gardens have the potential for attraction of people of the urban area and can act as suitable and desirable places for recreational activities of urban dwellers.

Table 2: The top reasons motivating participants to visit the gardens

\begin{tabular}{|c|c|c|c|c|c|c|}
\hline Rank & $\begin{array}{l}\text { Reasons for visiting } \\
\text { Golestan Garden }\end{array}$ & $f \quad \%$ & $\begin{array}{l}\text { Reasons for visiting Elgoli } \\
\text { Garden }\end{array}$ & $f$ & $\%$ & Rank \\
\hline 1 & Recreation and Exercise & 9032.02 & Recreation and Excercise & 107 & 45.14 & 1 \\
\hline 2 & Beautiful Place & 6924.55 & Enjoying the natural beauty & 81 & 34.18 & 2 \\
\hline 3 & Being with Family and Friends & 5820.65 & Meeting or Dating & 23 & 9.70 & 3 \\
\hline 4 & Enjoy the Natural Beauty & 3512.45 & Release Stress and Relaxation & 22 & 9.29 & 4 \\
\hline 5 & Release Stress and Relaxation & 2910.33 & $\begin{array}{l}\text { Nearby Restaurants or Service } \\
\text { Centers }\end{array}$ & 4 & 1.69 & 5 \\
\hline
\end{tabular}

\section{Conclusion}

The findings of this research revealed that the main reason of visiting both gardens (obtained from the responses of visitors) was the recreational purpose with 32.02 participants from Golestan Gardens and 45.14\% participants from Elgoli Garden. Most participants pointed to the suitable recreational potential of both gardens, reinforcing the hypothesis of this research which considered the main function of the both gardens to be related to the recreational attractions. Besides, in both gardens, the variety of physical elements and natural attractions enriches the character of population who visit the parks can also be considered as the major factors related to the importance of these two gardens.

Even though recreational attractions were the main reason for visitors of both parks, participants were also motivated to visit the both gardens by many other factors and features including natural landform and vegetation that can contribute to the improvement of human well-being in an urban park or area. From the viewpoint of problems and deficiencies, the highest comments ( $\mathrm{f}=28,9.96 \%$ ) by Golestan Garden's participants ware related to management including the lacking and maintenance of service facilities, while Elgoli park participants $(\mathrm{f}=62,26.17 \%)$ suggested more informative ideas, activities and facilities with the highest percentage. Both garden participants also commented about lack of parking facilities and need to fundamental improvements in safety and security of pedestrians and cleanliness. 
Table 3: Suggestions of participants for improvement of quality

\begin{tabular}{|c|c|c|c|c|c|c|}
\hline Rank & $\begin{array}{l}\text { Suggestions for Upgrading } \\
\text { the Golestan Garden }\end{array}$ & $f$ & $\%$ & Rank & $\begin{array}{l}\text { Suggestions for Upgrading } \\
\text { the Elgoli Garden }\end{array}$ & $f \quad \%$ \\
\hline 1 & Lacking facilities shall be added & 28 & 9.96 & 1 & $\begin{array}{l}\text { More informative ideas are } \\
\text { necessary }\end{array}$ & 6226.17 \\
\hline 2 & Provide more parking area & 27 & 9.60 & 2 & Upgrade the maintenance & 4619.41 \\
\hline 3 & Upgrade the maintenance & 72 & 25.62 & 3 & $\begin{array}{l}\text { Prohibit visitors from using } \\
\text { motorized vehicle }\end{array}$ & 3012.66 \\
\hline 4 & $\begin{array}{l}\text { Campaign to attract more } \\
\text { tourist }\end{array}$ & 26 & 9.28 & 4 & Provide more parking area & 177.18 \\
\hline 5 & $\begin{array}{l}\text { Cleanliness should be } \\
\text { prioritized }\end{array}$ & 23 & 8.18 & 5 & Vegetation is not attractive & 166.75 \\
\hline 6 & $\begin{array}{l}\text { Prohibit visitors from using } \\
\text { motorized vehicle }\end{array}$ & 45 & 16.01 & 6 & Improve Security & 145.90 \\
\hline 7 & Vegetation is not attractive & 34 & 12.09 & 7 & $\begin{array}{l}\text { Cleanliness should be } \\
\text { prioritized }\end{array}$ & 177.17 \\
\hline 8 & Improve Security & 8 & 2.84 & 8 & Vegetation is not attractive & 114.65 \\
\hline 9 & $\begin{array}{l}\text { Natural elements shall be } \\
\text { preserved }\end{array}$ & 12 & 4.27 & 9 & $\begin{array}{l}\text { Campaign to attract more } \\
\text { tourist }\end{array}$ & 156.32 \\
\hline 10 & Provide more open areas & 6 & 2.15 & 10 & $\begin{array}{l}\text { Natural elements shall be } \\
\text { preserved }\end{array}$ & $\begin{array}{ll}9 & 3.79\end{array}$ \\
\hline
\end{tabular}

Finally, from the survey and research findings, it can be concluded that urban parks and gardens can be a place for the urban dweller to avoid daily life stresses and leave behind urban activities as stress environment. Besides, urban parks and gardens can be a contributor for visitors in improving human well-being by connecting a human with natural elements. Negative comments by participants showed that visitors were alerted to the both urban parks condition that could contribute to visitor's perception and acceptance towards the level of an urban park. Therefore, both gardens management authorities should consider these issues to attract more visitors to come to the both gardens, since successful urban parks will provide positive benefits not only for the visitors but also for the residents of entire city, rather than adding to the pressure imposed by an urban life style.

\section{References}

Antrop, M., (1998). Landscape change: plan or chaos?. Landscape and Urban Planning, 41,155-161.

Badri Benam, N. \& Moosavi, M.S. (2012). An architectural approach to characterization of modern healthcare environments, J. Appl. Environ. Biol. Sci., 2(9)460-465.

Ekinci, Z., \& Sağlam, H., (2016). Meanings and social roles of the republic period urban parks in Ankara. Procedia - Social and Behavioral Sciences, 216 (2016) $610-621$.

Gopal, S., Tang, X., Phillips, N., Nomack, M., Pasquarella, V., \& Pitts, J., (2016). Characterizing urban landscapes using fuzzy sets. Computers, Environment and Urban Systems, 57 (2016) 212-223.

Gobster, P. H., Nassauer, J. I., Daniel, T. C., \& Fry, G., (2007). The shared landscape: What does aesthetics have to do with ecology?. Landscape Ecology, 22, 959-972.

Golzarian, M., \& Zarei, S., (2013). An analysis to role of gardens as urban space in historic structure of Tabriz. Journal of Basic and Applied Scientific Research, 3(6): 87-91. 
Hami, A., Suhardi Bin, M., Manohar, M., \& Shahhosseini, H., (2011). Users' preferences of usability and sustainability of old urban park in Tabriz. Iran. Australian Journal of Basic and Applied Sciences. 5 (11): 1899-1905.

Lelhaj, R. \& Moosavi, M.S. (2014). Considering the effect of gender on women's understanding of architectural spaces, European Online Journal of Natural and Social Sciences, 3 (4), 520-533. Openly accessible at http://www.european-science.com.

Lin, T., Sun, C., Li, X., Zhao, Q., Zhang, G., Ge, R., Ye, H., Huang, N., \& Yin, K., (2016). Spatial pattern of urban functional landscapes along an urban-rural gradient: A case study in Xiamen City, China. International Journal of Applied Earth Observation and Geoinformation, 46 (2016) 22-30.

Nassauer, J., (2012). Landscape as medium and method for synthesis in urban ecological design. Landscape and Urban Planning, 106 (2012) 221- 229.

Ragozino, S., (2016). Tools for regeneration of the urban landscape social enterprise as a link between people and landscape. Procedia- Social and Behavioral Sciences, 216 (2016)201- 208

Wu, J., (2006). Landscape ecology, cross-disciplinarity, and sustainability science. Landscape Ecology, 21, 1-4.

Wu, J., ( 2010). Landscape of culture and culture of landscape: does landscape ecology need culture? Landscape Ecology, 25, 1147-1150.

Wu, J., (2014). Urban ecology and sustainability: the state-of-the-science and future directions. Landscape and Urban Planning, 125, 209-221.

Zahedian, E. \& Moosavi, M.S. (2013). A morphological approach to characterization of urban space in historical structure of cities in Iran, J. Appl. Environ. Biol. Sci., 3(10) 59-66. 